\title{
COMT genotype and non-recovery after a whiplash injury in a Northern European population
}

\author{
Eric Rydman ${ }^{1 *}$ (D), Erika Comasco ${ }^{2}$, H. Pettersson ${ }^{1}$, L. Oreland ${ }^{2}$, S. Ponzer ${ }^{1}$ and C. Ottosson ${ }^{1}$
}

\begin{abstract}
Background: The COMT (Catechol-O-Methyl Transferase) gene may influence a person's vulnerability to develop long-term pain and some COMT single nucleotide polymorphisms (SNPs) may associate with patterns of acute or chronic pain. Many patients with whiplash-associated disorders (WADs) suffer from long-term pain and other related symptoms, but it is less known if genetic factors play a role in the recovery process. The primary aim of this study was to evaluate whether self-reported non-recovery, including pain, was related to COMT genotype in patients with WAD. The secondary aim was to investigate whether or not background factors, including mental health, were related to genotype and non-recovery.

Methods: A total of 133 patients with neck pain after a whiplash trauma were included. Background factors were collected and blood samples were taken during the acute phase after the accident. DNA was isolated from blood and used to genotype the SNPs rs6269, rs4633, rs4818 and rs4680 in the COMT gene; additionally haplotypes were estimated and haplogenotypes inferred. The patients were followed up after 12 months and asked to rate their recovery including pain, mental health and quality of life.
\end{abstract}

Results: The overall reported non-recovery rate at 12 months was $44 \%$ with no significant differences in distribution of the COMT haplotypes. High levels of self-reported pain (OR 7.2) and anxiety (OR 4.4) after the accident were associated with non-recovery, but not related to the haplotypes. None of the other background factors were related to the haplotypes or non-recovery.

Conclusion: No association between self-reported non-recovery or pain levels and COMT haplotypes in patients with acute whiplash injuries could be detected. Independent replications are necessary to discard the hypothesis that COMT haplotypes do not influence non-recovery or pain levels in patients with acute whiplash injuries. High levels of initial pain and anxiety were associated with non-recovery, thereby confirming previously published reports.

Keywords: Whiplash, Wad, COMT, Catechol O-methyltransferase, Pain, Genetics, Recovery

\section{Background}

Despite several attempts to understand the differences in the prognosis of recovery after a whiplash trauma, the biological mechanisms remain unexplained. The main symptom in patients with a whiplash-associated disorder (WAD) is long-lasting pain [1]. Initial pain sensations

\footnotetext{
* Correspondence: eric.rydman@ki.se

${ }^{1}$ Department of Clinical Science and Education, Södersjukhuset, Karolinska Institutet, -118 83 Stockholm, SE, Sweden

Full list of author information is available at the end of the article
}

after the trauma seem to be the best prognostic factors for the outcome in patients suffering from WAD [2-5].

It has been suggested that genetic predisposition might play a role in the pathogenesis of WAD. In the field of pain genetics, the catechol-O-methyltransferase (COMT) gene is one of the most well-studied ones [6]. It has been suggested that polymorphisms within the gene regulate pain perception in healthy subjects [7], as well as in patients with fibromyalgia $[8,9]$, lower back pain $[9,10]$ and also acute pain after motor vehicle accidents [11]. Tammimäki and Männistö's review of the literature 
indicated that diverging results from published studies call for further investigations, especially in the field of musculoskeletal pain [12].

The COMT gene regulates formation of both soluble and membrane-bound protein isoforms. It contains many single nucleotide polymorphisms (SNPs), some of which have been investigated concerning their role in pain regulation. The COMT Val158Met SNP, rs4680, is the most frequently investigated variant [9]. The Met/ Met genotype of the SNP rs4680 has been associated with several mental diseases [13], as well as fibromyalgia and widespread pain [14]. In addition, the importance of haplotypes has been demonstrated, especially regarding the haplotype that includes rs6269, coding for the soluble form, and rs4633, rs4680 and rs4818, coding for both the soluble and membrane-bound forms. Three common haplotypes based on linkage disequilibrium and pain-related data have been identified [15]. The low pain sensitivity (LPS) haplotype codes for the highest levels of the COMT enzyme activity and has been suggested to mediate for high tolerance of musculoskeletal pain. The average pain sensitivity (APS) haplotype codes for lower enzyme activity and average pain tolerance. The high pain sensitivity (HPS) haplotype is known to code for the lowest levels of the enzyme and the lowest tolerance of pain $[15,16]$.

While the COMT gene contains functional polymorphisms that have been found to influence human pain [17-19], its role in WAD is not known. Because of the relationship between initial pain sensation and recovery in WAD patients [20], it is plausible to hypothesize that COMT variations could influence pain regulation and clinical outcome in this patient population.

The primary aim of this study was to evaluate whether or not self-reported non-recovery, including pain, was related to COMT genotype in patients with WAD. The secondary aim was to investigate whether or not background factors, including mental health, were related to haplotypes and to non-recovery.

\section{Methods}

\section{Participants}

Patients were enrolled between September 2002 and January 2004. Potentially eligible patients had sustained a whiplash injury less than $24 \mathrm{~h}$ before arrival at the emergency department (ED). Exclusion criteria were WAD IV (fractures), age $<15$ years, inability to read and understand the Swedish language and impaired cognitive function making the self-report impossible. The medical treatment was administered according to the routine protocols at the hospital. The patients were informed about the study and those who agreed to participate were invited to an out-patient visit for inclusion. The patients were originally part of a randomized controlled trial in which standard treatment was compared with an intervention [21].

A blood sample for the genetic analysis was taken and the participants were asked to fill in questionnaires regarding socio-demographic information, including age $(<24,25-65,>66)$, gender, educational level (high school or less or university), working status, marital status and ethnic background (Caucasian, Caucasian-Hispanic, Asian, Middle Eastern or African). They were asked to rate their health-related quality of life (HRQoL) the week before the accident (i.e., a retrospective rating) according to the Short Form-36 (SF-36) Health Survey [22]. Visual analogue scales (VAS) were used for ratings of pain and mental status (anxiety and depression) the week before the whiplash injury occurred (i.e., a retrospective rating) and at the time of inclusion, with 0 indicating minimum and 100 maximum symptoms. The patients also filled in the Hospital Anxiety and Depression (HAD) [23] and the Posttraumatic Stress Disorder (PTSD-10) questionnaires [24]. A score of $>10$ indicated a state of anxiety or depression on the HAD score [25] and a score of $>5$ indicated PTSD according to PTSD-10 [26]. These selfreported data did not, however, fulfil the criteria for the medical conditions per se.

\section{Genetic analysis}

Blood was used to isolate DNA using the QIAamp DNA MiniKit, according to the manufacturer's protocol (http://www.qiagen.com/). The selected polymorphisms in the COMT gene were: rs6269, rs4633, rs4818 and rs4680. The COMT rs4680 ( $\mathrm{Val}^{158} \mathrm{Met}$ ) polymorphism was genotyped using the TaqMan ${ }^{\bullet}$ Drug Metabolism Genotyping Assay, according to the manufacturer's protocol [27]. This assay consists of sequence-specific forward and reverse primers and two TaqMan ${ }^{\circ}$ MGB probes, each labelled with a $\mathrm{FAM}^{\mathrm{rm}}$ or $\mathrm{VIC}^{\ominus}$ reporter dye at the 5'end and a non-fluorescent quencher at the 3'end of each one. Polymerase chain reaction (PCR) was performed in a 5 - $\mu$ l reaction mixture containing $1 \times$ TaqMan $^{\circ}$ Universal PCR Master Mix $2.5 \mu \mathrm{l}$; 40× TaqMan ${ }^{\circ}$ rug Metabolism Genotyping Assay Mix $0.25 \mu \mathrm{l}$ and 3-20 ng Genomic DNA diluted in $\mathrm{H}_{2} \mathrm{O}$ (Applied Biosystem ${ }^{\circ}$ ). An ABI PRISM $^{\circledR} 7900 H T$ Sequence Detection System was used to perform allele discrimination PCR reactions according to the following thermal cycler conditions: initial step of $10 \mathrm{~min}$ at $95{ }^{\circ} \mathrm{C}$, followed by 50 cycles of denaturation at $15 \mathrm{~s}, 92{ }^{\circ} \mathrm{C}$ and annealing at $90 \mathrm{~s}, 60^{\circ} \mathrm{C}$. The PCR products were analysed and allele sizes were determined using SDS 2.2 (Applied Biosystem ${ }^{\circ}$ ). On the other hand, a fluorescence-based competitive allele-specific PCR (KASPar) assay (KBioscience ${ }^{\circ}$ ), based on a public genome sequence (www.ensembl.org/), was used to analyse the SNPs rs6269, rs4633 and rs4818. Alleles were determined using SNPviewer2 ${ }^{\circ} \cdot X^{2}$ test or Fisher's test was 
used to investigate deviations from Hardy-Weinberg Equilibrium (HWE). The EM algorithm was computed using SNP \& Variation Suite 7 (Golden Helix) to estimate linkage disequilibrium $\left(\mathrm{r}^{2}\right)$ and haplotype blocks. Three common haplotypes were found, as in Diatchenko et al. [15]. LPS was defined as homozygous for the G_C_G_G haplotype (GCGG/GCGG). APS was defined as homozygous for the A_T_C_A haplotype (ATCA/ATCA) and heterozygous for ACCG/GCGG or GCCG/ATCA. HPS was defined as heterozygous for ATCA or ACCG.

An additional categorization of genotypes was determined according to the presence of at least one LPS haplotype [11].

\section{Outcome measures}

The primary outcome measure was self-reported recovery at 12 months, assessed by means of the single question: 'Do you feel recovered after the injury?' (Yes/No). Secondary outcome measures were the SF-36 responses (physical and mental score) and pain and mental status measured by visual analogue scales (VAS pain and VAS mental).

\section{Statistical methods}

Nominal variables were tested with chi-square test. The Kruskal-Wallis and Anova were used for comparisons measured on interval and ratio scale variables. The results were regarded as significant if $p$ was less than 0.05 , two-tailed. The $p$-values were presented without adjustment for multiple comparisons. Logistic regression was used to identify variables associated with being risk factors for non-recovery at 12 months. First, crude associations for each selected variable were studied in univariable models. Secondly, a multivariable model was used to adjust the associations. The results were regarded as significant at $p<0.05$. The associations are presented as odds ratios (ORs) with 95\% confidence intervals [28].

The statistical analysis was performed using SPSS version 20.0 (SPSS, Inc., Chicago, Il. USA).

\section{Ethics}

The study was approved by the Regional Research Ethics Committee Stockholm, Sweden and all patients gave their written informed consent before inclusion (Dnr-240/01).

\section{Results}

A total of 133 patients were enrolled in our study, but the outcome analysis was based on 128 patients because five lacked 12-month follow-up data. The distribution of genotypes and haplotypes are presented in Table 1. Most of the patients had the APS haplotype (102 out of 133).
Table 1 Distribution of genotypes and haplotypes for the study population $(n=133)$

\begin{tabular}{|c|c|c|c|c|}
\hline & Genotype & $n=133$ & $\%$ & $\begin{array}{l}\text { HWE test } \\
p \text {-value }\end{array}$ \\
\hline \multicolumn{5}{|l|}{ SNP } \\
\hline \multirow[t]{3}{*}{ rs6269 } & $\mathrm{A} / \mathrm{A}$ & 56 & 42 & $\begin{array}{l}x^{2}=0.75 \\
p=0.39\end{array}$ \\
\hline & $A / G$ & 57 & 43 & \\
\hline & $\mathrm{G} / \mathrm{G}$ & 20 & 15 & \\
\hline \multirow[t]{3}{*}{ rs4633 } & $\mathrm{C} / \mathrm{C}$ & 29 & 22 & $\begin{array}{l}x^{2}=2.14 \\
p=0.14\end{array}$ \\
\hline & $\mathrm{C} / \mathrm{T}$ & 57 & 43 & \\
\hline & $\mathrm{T} / \mathrm{T}$ & 47 & 35 & \\
\hline \multirow[t]{3}{*}{ rs4818 } & $\mathrm{C} / \mathrm{C}$ & 59 & 44 & $\begin{array}{l}x^{2}=0.64 \\
p=0.42\end{array}$ \\
\hline & $C / G$ & 56 & 42 & \\
\hline & $\mathrm{G} / \mathrm{G}$ & 18 & 14 & \\
\hline \multirow[t]{3}{*}{ rs4680 } & $\mathrm{A} / \mathrm{A}$ & 47 & 35 & $\begin{array}{l}x^{2}=2.75 \\
p=0.09\end{array}$ \\
\hline & $\mathrm{A} / \mathrm{G}$ & 56 & 42 & \\
\hline & $\mathrm{G} / \mathrm{G}$ & 30 & 23 & \\
\hline \multicolumn{5}{|l|}{ Haplotype } \\
\hline LPS & GCGG/GCGG & 20 & 15 & \\
\hline APS & $\begin{array}{l}\text { ATCA/ATCA ACCG/GCGG } \\
\text { or GCCG/ATCA }\end{array}$ & 102 & 77 & \\
\hline HPS & ATCA or ACCG & 11 & 8 & \\
\hline
\end{tabular}

As shown in Tables 2, 56\% of the patients were females; the mean age was 40 years and most of the patients were of Caucasian origin, had a secondary school education, were working and were non-smokers. There were no differences regarding these background factors and the distribution of LPS, APS and HPS haplotypes (Table 2). Mental health data at inclusion showed that $20.2 \%$ of the patients had self-reported symptoms of anxiety and $8.7 \%$ had signs of PTSD before the whiplash injury, but there were no significant differences between the different haplotypes and these factors as also shown in Table 2.

No significant differences could be detected either between the distribution of haplotypes and the VAS and SF-36 results before (retrospective rating) or after the accident or at the 12-month follow-up (Fig. 1), (Table 3).

Fifty-six patients $(43.8 \%)$ reported non-recovery at 12 months, with no difference in the recovery rate between the different COMT haplotypes (LPS $42.1 \%$, APS $43.9 \%$ and HPS $45.5 \%$, respectively).

Regression analyses with adjustments for confounding factors (Table 4) showed no significant differences regarding the COMT haplotypes in relation to recovery, but high levels of initial pain according to VAS (adjusted OR, 10.4 (3.0-36.6) and anxiety according to HAD 
Table 2 Background data at baseline $(n=133)$. There were no significant differences in any of the comparisons between the variables

\begin{tabular}{|c|c|c|c|c|}
\hline & $\begin{array}{l}\text { Total } \\
\mathrm{n}=133(\%)\end{array}$ & $\begin{array}{l}\text { LPS } \\
n=20(\%)\end{array}$ & $\begin{array}{l}\text { APS } \\
n=102(\%)\end{array}$ & $\begin{array}{l}\text { HPS } \\
n=11(\%)\end{array}$ \\
\hline Female sex & $75(56)$ & $11(55)$ & $57(56)$ & $7(64)$ \\
\hline \multicolumn{5}{|l|}{ Ethnicity } \\
\hline Caucasian & $114(86)$ & $17(15)$ & $88(77)$ & $9(8)$ \\
\hline Caucasian-Hispanic & $7(5)$ & $1(14)$ & $6(85)$ & $0(0)$ \\
\hline Asian & $2(1)$ & $1(50)$ & $0(0)$ & $1(50)$ \\
\hline Middle Eastern & $9(7)$ & $1(11)$ & $8(89)$ & $0(0)$ \\
\hline African & $1(1)$ & $0(0)$ & $0(0)$ & $1(100)$ \\
\hline \multicolumn{5}{|l|}{ Educational level } \\
\hline High school & $92(69)$ & $15(75)$ & $71(70)$ & $6(55)$ \\
\hline University & $41(31)$ & $5(25)$ & $31(30)$ & $5(45)$ \\
\hline Employed (yes) & $109(82)$ & $15(75)$ & $85(83)$ & $9(82)$ \\
\hline Smoker (yes) & $34(26)$ & $5(26)$ & $27(28)$ & $2 / 18)$ \\
\hline Self-ratings of mental health & n (\%) & $n$ & $n$ & $\mathrm{n}$ \\
\hline HAD depression (yes) & $12(9.8)$ & 2 & 8 & 2 \\
\hline HAD anxiety (yes) & $24(20.2)$ & 3 & 20 & 1 \\
\hline PTSD (yes) & $11(8.7)$ & 3 & 7 & 1 \\
\hline \multirow[t]{2}{*}{ Age (years) } & mean (SD) & mean (SD) & mean (SD) & mean (SD) \\
\hline & $40(13)$ & $43(18)$ & $40(13)$ & $41(15)$ \\
\hline
\end{tabular}

ratings (adjusted OR, $3.5(1.1-11.6)$ were associated with non-recovery at 12 months.

\section{Discussion}

This study, investigating the association between COMT haplotypes and recovery after whiplash injuries, could not detect any differences in the recovery rate between the three COMT haplotypes. Nor were any significant differences detected between COMT haplotypes regarding the secondary outcome measures, i.e., level of pain and quality of life according to the SF-36 at 12 months. However, the multivariate analysis showed that high levels of pain and anxiety after the whiplash injury were significantly associated with non-recovery.

In a meta-analysis by Tammimäki et al. of pain and psychological symptoms after motor vehicle collisions, an association was found between different COMT haplotypes and musculosceletal pain [12]. Furthermore, they

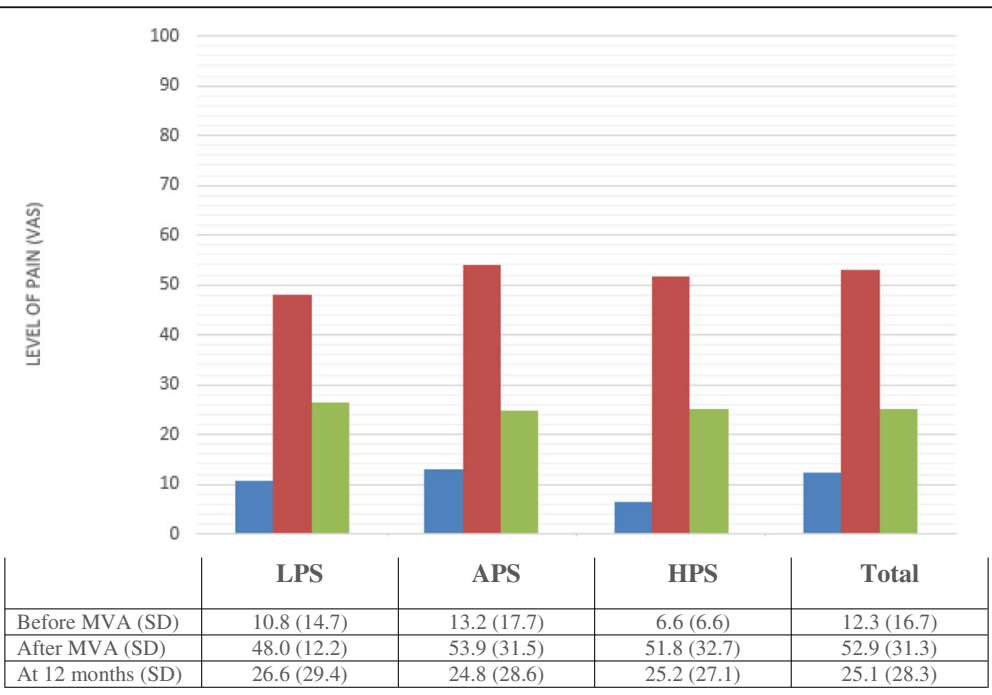

Fig. 1 Association between haplotypes reported before the accident, after the accident and at 12- month follow-up and mean levels of pain 
Table 3 Pain and mental status ratings on Visual Analogue Scale (VAS) and HRQoL according to SF-36 in relation to haplotype. No significant differences between the haplotype groups

\begin{tabular}{|c|c|c|c|c|c|c|c|c|}
\hline & \multicolumn{2}{|l|}{ LPS } & \multicolumn{2}{|l|}{ APS } & \multicolumn{2}{|l|}{ HPS } & \multicolumn{2}{|l|}{ Total } \\
\hline & Mean & SD & Mean & SD & Mean & SD & Mean & SD \\
\hline \multicolumn{9}{|l|}{ VAS pain } \\
\hline Before & 10.85 & 14,67 & 13.16 & 17.73 & 6.55 & 6.55 & 12.26 & 16.68 \\
\hline After & 48.00 & 31.21 & 53.94 & 31.46 & 51.82 & 32.66 & 52.87 & 31.35 \\
\hline At 12 months & 26.59 & 29.36 & 24.83 & 28.57 & 25.20 & 27.09 & 25.14 & 28.32 \\
\hline \multicolumn{9}{|l|}{ VAS mental health } \\
\hline Before & 20.40 & 30.39 & 11.40 & 17.11 & 15.82 & 19.82 & 13.13 & 19.96 \\
\hline After & 41.35 & 33.47 & 38.19 & 32.96 & 32.18 & 31.47 & 38.17 & 32.74 \\
\hline At 12 months & 17.12 & 22.63 & 16.10 & 27.73 & 16.40 & 21.99 & 16.28 & 26.34 \\
\hline \multicolumn{9}{|l|}{ SF-36 physical score } \\
\hline Before & 89.74 & 12.34 & 87.59 & 15.74 & 88.18 & 13.41 & 87.97 & 14.98 \\
\hline At 12 months & 71.13 & 27.20 & 72.54 & 28.86 & 73.53 & 25.84 & 72.40 & 28.01 \\
\hline \multicolumn{9}{|l|}{ SF-36 mental score } \\
\hline Before & 88.12 & 12.68 & 85.47 & 14.46 & 90.69 & 3.22 & 86.32 & 13.64 \\
\hline At 12 months & 73.75 & 29.58 & 72.92 & 26.43 & 69.83 & 19.08 & 72.70 & 26.00 \\
\hline
\end{tabular}

noted that several other factors, such as pain stimulus, chronicity of pain, sex, sampling and sample size, were identified as contributors to differences in their results. McLean and co-workers [11] reported on pain and psychological symptoms after motor vehicle collisions and found a connection with the pain sensitive COMT genotype. In our study, pain and anxiety affected the outcome, but were not connected to the COMT haplotypes. It is possible that the finding that $20 \%$ of the respondents reported symptoms of anxiety and 9\% had signs of PTSD prior to the accident affected the results. It has previously been shown that anxiety and PTSD symptoms can moderate pain sensations [29, 30].

Another explanation for the findings in this study, as compared to previous research, could be the differences in ethnicity between the studies. Mclean et al. reported differences in pain perception in a European-American population [11], Xiang et al. could not detect any

Table 4 Association between the predictor variables and self-reported non-recovery at 12 months after the injury. All predictor variables were measured at baseline. Odds ratios and 95\% confidence intervals (Cls)

\begin{tabular}{|c|c|c|c|c|c|}
\hline \multirow{2}{*}{$\begin{array}{l}\text { Predictor variable } \\
\text { Gender }\end{array}$} & \multirow{2}{*}{$\begin{array}{l}\text { Level } \\
\text { Male }\end{array}$} & \multicolumn{2}{|c|}{$\begin{array}{l}\text { Non-recovered/total } \\
(\mathrm{n} / \mathrm{n}) \%\end{array}$} & \multirow{2}{*}{$\begin{array}{l}\text { Odds ratio }(\mathrm{Cl}) \\
\text { Crude } \\
1.0 \text { (Reference) }\end{array}$} & \multirow[t]{2}{*}{$\begin{array}{l}\text { Odds ratio (Cl) } \\
\text { Adjusted }^{\mathrm{a}}\end{array}$} \\
\hline & & $23 / 54$ & 42.6 & & \\
\hline & Female & $33 / 74$ & 44.6 & $1.1(0.5-2.2)$ & $1.2(0.5-3.0)$ \\
\hline \multirow[t]{3}{*}{ Age } & $<24$ & $6 / 13$ & 46.2 & 1.0 (Reference) & \\
\hline & $25-65$ & $49 / 110$ & 44.5 & $0.9(0.3-3.0)$ & $0.7(0.2-2.7)$ \\
\hline & $>66$ & $1 / 5$ & 20.0 & $0.3(0.02-3.4)$ & $0.1(0.0-1.4)$ \\
\hline \multirow[t]{3}{*}{ VAS pain after accident } & $<24$ & $7 / 35$ & 20.0 & 1.0 (Reference) & \\
\hline & $25-65$ & $13 / 37$ & 35.1 & $2.2(0.7-6.3)$ & $2.8(0.9-8.8)$ \\
\hline & $>65$ & $36 / 56$ & 64.3 & $7.2(2.7-19.4)$ & $10.4(3.0-36.6)$ \\
\hline \multirow[t]{2}{*}{ Anxiety (HAD) } & No & $35 / 93$ & 37.6 & 1.0 (Reference) & \\
\hline & Yes & $16 / 22$ & 72.7 & $4.4(1.6-12.4)$ & $3.5(1.1-11.6)$ \\
\hline \multirow[t]{3}{*}{ Haplotype } & LPS & $8 / 19$ & 42.1 & 1.0 (Reference) & \\
\hline & APS & $43 / 98$ & 43.9 & $1.1(0.4-2.9)$ & $0.8(0.2-2.5)$ \\
\hline & HPS & $5 / 11$ & 45.5 & $1.2(2.3-5.1)$ & $0.9(0.2-5.6)$ \\
\hline \multirow[t]{2}{*}{ Treatment } & No & $39 / 91$ & 42.9 & 1.0 (Reference) & \\
\hline & Yes & $15 / 32$ & 46.9 & $1.2(0.5-2-6)$ & $0.4(0.1-1.2)$ \\
\hline
\end{tabular}


differences in pain perception in a Chinese population [31], while, in the present study, almost $90 \%$ of the participants consists of Caucasians. One limitation of this study is the lack of a control group. The distribution of COMT haplotypes varies between different settings and geographic locations $[8,32]$ and may affect the outcome. Furthermore, gender differences are also relevant in this field of research [33]. Indeed, several studies point towards a complex COMT-by-gender interaction effect $[34,35]$. However, in our study, no difference could be detected between the sexes, probably due to a small sample size.

Nor could our study demonstrate any differences in pain ratings between patients with the most common COMT genotypes. This finding is in contrast to the findings by Bortsov and co-workers, who found differences between genotypes 6 weeks after a motor vehicle collision [36]. One reason might be the different methods of $C O M T$ haplotyping and subgrouping compared to that cohort. Grouping into three haplotypes (i.e., LPS; APS; HPS) was done as suggested by Diatchenko and colleagues [15]. Another reason for the contradictory findings might be differences in self-reporting methodology (verbal vs. VAS) and the timing for rating pain. In our study, the pain ratings were done within two weeks after the accident, a time point at which the level of pain still might not have been stabilized and the frequency of high pain ratings were high and, consequently, could lead to a poorer outcome $[4,37]$.

Pain recovery comprises a complex interplay between several systems, from sensory to immune to brain circuits [38]. Research on genetic susceptibility to pain has identified several COMT SNPs as possible candidates; however, more studies are needed to define the possible causality of this relationship.

\section{Conclusion}

In summary, no relationship between the outcome regarding reported non-recovery or pain levels and COMT haplotypes in patients with acute whiplash injuries could be detected in this material. Nor did we find associations between psychological factors and the COMT haplotypes. High levels of initial pain and anxiety were associated with non-recovery, thereby confirming previously published literature.

\section{Abbreviations}

APS: Average Pain Sensitivity; COMT: Catechol-O-Methyl Transferase; HPS: High Pain Sensitivity; LPS: Low Pain Sensitivity; PTSD: Posttraumatic Stress Disorder; SNP: Single Nucleotide Polymorphism; VAS: Visual Analogue Scale; WAD: Whiplash-Associated Disorder

\section{Funding}

This study was supported by the Stockholm County through grants for the Department of Orthopedics for research, development and education (FoUU-medel).

\section{Availability of data and materials}

The data and materials in the current paper can be made available upon request by sending an e-mail to the first author.

\section{Authors' contributions}

ER participated in the design of the study, carried out the statistical analysis and participated in the process of writing the manuscript. EC performed the genetic analysis and contributed to the writing of the Methods section of the manuscript and was also involved in the writing of the Discussion. HP participated in the statistical analysis. LO was involved in the study design and the collection of genetic material. SP contributed to the collection of data and participated in the writing of the manuscript and the design and analysis of the results. CO contributed to the collection of data, the statistical analysis and the writing of the manuscript. All authors read and approved the final manuscript.

\section{Ethics approval and consent to participate}

The study was approved by the Regional Research Ethics Committee Stockholm, Sweden and all patients gave written consent before inclusion (Dnr-240/01).

\section{Consent for publication}

Not applicable.

\section{Competing interests}

The authors declare that they have no competing interests.

\section{Publisher's Note}

Springer Nature remains neutral with regard to jurisdictional claims in published maps and institutional affiliations.

\section{Author details}

${ }^{1}$ Department of Clinical Science and Education, Södersjukhuset, Karolinska Institutet, -118 83 Stockholm, SE, Sweden. 'Department of Neuroscience, Uppsala University, Uppsala, Sweden.

Received: 6 September 2016 Accepted: 6 November 2017

Published online: 01 December 2017

\section{References}

1. Bannister G, Amirfeyz R, Kelley S, Gargan M. Whiplash injury. The Journal of bone and joint surgery British volume. 2009;91(7):845-50.

2. Cassidy JD, Carroll L, Cote P, Lemstra M, Berglund A, Nygren A. Effect of eliminating compensation for pain and suffering on the outcome of insurance claims for whiplash injury. N Engl J Med. 2000;342(16):1179-86.

3. Partheni M, Constantoyannis C, Ferrari R, Nikiforidis G, Voulgaris S, Papadakis NA. Prospective cohort study of the outcome of acute whiplash injury in Greece. Clin Exp Rheumatol. 2000;18(1):67-70.

4. Carroll LJ, Holm LW, Hogg-Johnson S, Cote P, Cassidy JD, Haldeman S, et al. Course and prognostic factors for neck pain in whiplash-associated disorders (WAD): results of the bone and joint decade 2000-2010 task force on neck pain and its associated disorders. Spine (Phila Pa 1976). 2008;33(4 Suppl):S83-92.

5. Williams M, Williamson E, Gates S, Lamb S, Cooke MA. Systematic literature review of physical prognostic factors for the development of late whiplash syndrome. Spine (Phila Pa 1976). 2007;32(25):E764-80.

6. Mogil JS. Pain genetics: past, present and future. Trends Genet. 2012;

7. Zubieta JK, Heitzeg MM, Smith YR, Bueller JA, Xu K, YJ X, et al. COMT val(158)met genotype affects mu-opioid neurotransmitter responses to a pain stressor. Science. 2003;299(5610):1240-3.

8. Martinez-Jauand M, Sitges C, Rodriguez V, Picornell A, Ramon M, Buskila D, et al. Pain sensitivity in fibromyalgia is associated with catechol-Omethyltransferase (COMT) gene. Eur J Pain. 2012;

9. Finan PH, Zautra AJ, Davis MC, Lemery-Chalfant K, Covault J, Tennen HCOMT. Moderates the relation of daily maladaptive coping and pain in fibromyalgia. Pain. 2011;152(2):300-7. 
10. Jacobsen LM, Schistad El, Storesund A, Pedersen LM, Rygh LJ, Roe C, et al. The COMT rs4680 met allele contributes to long-lasting low back pain, sciatica and disability after lumbar disc herniation. Eur J Pain. 2012;

11. McLean SA, Diatchenko L, Lee YM, Swor RA, Domeier RM, Jones JS, et al. Catechol O-methyltransferase haplotype predicts immediate musculoskeletal neck pain and psychological symptoms after motor vehicle collision. J Pain. 2011;12(1):101-7.

12. Tammimaki A, Mannisto PT. Catechol-O-methyltransferase gene polymorphism and chronic human pain: a systematic review and metaanalysis. Pharmacogenet Genomics. 2012;22(9):673-91.

13. Bertolino A, Caforio G, Blasi G, De Candia M, Latorre V, Petruzzella V, et al. Interaction of COMT ( $\mathrm{Val}(108 / 158)$ met) genotype and olanzapine treatment on prefrontal cortical function in patients with schizophrenia. Am J Psychiatry. 2004;161(10):1798-805

14. Cohen H, Neumann L, Glazer Y, Ebstein RP, Buskila D. The relationship between a common catechol-O-methyltransferase (COMT) polymorphism val(158) met and fibromyalgia. Clin Exp Rheumatol. 2009;27(5 Suppl 56):S51-6.

15. Diatchenko L, Slade GD, Nackley AG, Bhalang K, Sigurdsson A, Belfer I, et al. Genetic basis for individual variations in pain perception and the development of a chronic pain condition. Hum Mol Genet. 2005;14(1):135-43.

16. Diatchenko L, Nackley AG, Slade GD, Bhalang K, Belfer I, Max MB, et al. Catechol-O-methyltransferase gene polymorphisms are associated with multiple pain-evoking stimuli. Pain. 2006;125(3):216-24.

17. George SZ, Wallace MR, Wright TW, Moser MW, Greenfield WH, 3rd, Sack BK, et al. Evidence for a biopsychosocial influence on shoulder pain: pain catastrophizing and catechol-O-methyltransferase (COMT) diplotype predict clinical pain ratings. Pain 2008;136(1-2):53-61.

18. Nackley AG, Diatchenko L. Assessing potential functionality of catechol-Omethyltransferase (COMT) polymorphisms associated with pain sensitivity and temporomandibular joint disorders. Methods Mol Biol. 2010;617:375-93.

19. van Esch AA, de Vries E, Te Morsche RH, van Oijen MG, Jansen JB, Drenth JP. Catechol-O-methyltransferase (COMT) gene variants and pain in chronic pancreatitis. Neth J Med. 2011;69(7):330-4

20. Walton DM, Carroll $\amalg$, Kasch H, Sterling M, Verhagen AP, Macdermid JC, et al. An overview of systematic reviews on prognostic factors in neck pain: results from the international collaboration on neck pain (ICON) project. The open orthopaedics journal. 2013;7:494-505.

21. Ottosson C, Pettersson H, Johansson SE, Nyren O, Ponzer S. Recovery after minor traffic injuries: a randomized controlled trial. PLoS clinical trials. 2007; 2(3):e14.

22. Sullivan M, Karlsson J. The Swedish SF-36 health survey III. Evaluation of criterion-based validity: results from normative population. J Clin Epidemiol. 1998:51(11):1105-13.

23. Zigmond AS, Snaith RP. The hospital anxiety and depression scale. Acta Psychiatr Scand. 1983;67(6):361-70.

24. Jubran A, Lawm G, Duffner LA, Collins EG, Lanuza DM, Hoffman LA, et al Post-traumatic stress disorder after weaning from prolonged mechanical ventilation. Intensive Care Med. 2010;36(12):2030-7.

25. Bodlund O, Andersson SO, Mallon L. Effects of consulting psychiatrist in primary care. 1-year follow-up of diagnosing and treating anxiety and depression. Scand J Prim Health Care. 1999;17(3):153-7.

26. Thulesius H, Alveblom AK, Hakansson A. Post-traumatic stress associated with low self-rated well-being in primary care attenders. Nordic journal of psychiatry. 2004;58(4):261-6.

27. Comasco E, Hellgren C, Sundstrom-Poromaa I. Influence of catechol-Omethyltransferase Val158Met polymorphism on startle response in the presence of high estradiol levels. European neuropsychopharmacology : the journal of the European College of Neuropsychopharmacology. 2013;23(7):629-35.

28. Chang PC, Procissi D, Bao Q, Centeno MV, Baria A, Apkarian AV. Novel method for functional brain imaging in awake minimally restrained rats. J Neurophysiol 2016:jn. 2015:01078.

29. Schwahn C, Grabe HJ. Meyer zu Schwabedissen H, Teumer a, Schmidt CO, brinkman C, et al. the effect of catechol-O-methyltransferase polymorphisms on pain is modified by depressive symptoms. Eur J Pain. 2012:16(6):878-89.

30. Jenewein J, Erni J, Moergeli H, Grillon C, Schumacher S, Mueller-Pfeiffer C, et al. Altered pain perception and fear-learning deficits in subjects with posttraumatic stress disorder. J Pain. 2016;17(12):1325-33.

31. Xiang $X$, Jiang $Y$, Ni Y, Fan M, Shen F, Wang X, et al. Catechol-Omethyltransferase polymorphisms do not play a significant role in pain perception in male Chinese Han population. Physiol Genomics. 2012;44(5): 318-28.
32. Park DJ, Kim SH, Nah SS, Lee JH, Kim SK, Lee YA, et al. Association between catechol-O-methyl transferase gene polymorphisms and fibromyalgia in a Korean population: a case-control study. Eur J Pain. 2016;20(7):1131-9.

33. Belfer I, Segall SK, Lariviere WR, Smith SB, Dai F, Slade GD, et al. Pain modality- and sex-specific effects of COMT genetic functional variants. Pain. 2013;154(8):1368-76.

34. Harrison PJ, Tunbridge EM. Catechol-O-Methyltransferase (COMT): a gene contributing to sex differences in brain function, and to sexual dimorphism in the predisposition to psychiatric disorders. Neuropsychopharmacology 2008;33(13):3037-3045

35. Gogos JA, Morgan M, Luine V, Santha M, Ogawa S, Pfaff D, et al. CatecholO-methyltransferase-deficient mice exhibit sexually dimorphic changes in catecholamine levels and behavior. Proc Natl Acad Sci U S A. 1998;95(17): 9991-6.

36. Bortsov AV, Diatchenko L, McLean SA. Complex multilocus effects of catechol-O-Methyltransferase haplotypes predict pain and pain interference 6 weeks after motor vehicle collision. NeuroMolecular Med. 2013;

37. Sterling M. Whiplash-associated disorder: musculoskeletal pain and related clinical findings. 2011.

38. Vachon-Presseau E, Tetreault P, Petre B, Huang L, Berger SE, Torbey S, et al. Corticolimbic anatomical characteristics predetermine risk for chronic pain. Brain : a journal of neurology. 2016;

\section{Submit your next manuscript to BioMed Central and we will help you at every step:}

- We accept pre-submission inquiries

- Our selector tool helps you to find the most relevant journal

- We provide round the clock customer support

- Convenient online submission

- Thorough peer review

- Inclusion in PubMed and all major indexing services

- Maximum visibility for your research

Submit your manuscript at www.biomedcentral.com/submit
) Biomed Central 